\title{
Dose-Response Association Between Dietary Folate and Niacin Intakes With Diabetes Among Chinese Adults: A Cross-Sectional Study
}

\author{
Yuhong Jiang \\ Bengbu Medical College \\ Zhiwen Zhang \\ Bengbu Medical College \\ Yi Zhu \\ Bengbu Medical College \\ Yongfei Chai \\ Bengbu Medical College \\ Hong Xie ( $\nabla$ xh@bbmc.edu.cn ) \\ Bengbu Medical College
}

\section{Research article}

Keywords: Dietary intake, Vitamins, Diabetes, Middle-aged Chinese

Posted Date: November 15th, 2021

DOI: https://doi.org/10.21203/rs.3.rs-1063880/v1

License: @ (i) This work is licensed under a Creative Commons Attribution 4.0 International License. Read Full License 


\section{Abstract \\ Background}

This study aimed to examine the relationships between dietary vitamin intakes and the risk of diabetes among Chinese adults.

\section{Methods}

This is a cross-sectional observational study. Demographic and anthropometric data along with information on dietary vitamin intakes were collected and eligible participants were recruited to complete a questionnaire. Binary logistic regression analysis was conducted to examine the associations between dietary vitamin intakes and the risk of diabetes, with adjustment for potential confounders. We also evaluated non-linear dose-response relationships between dietary vitamin intakes and diabetes using adjusted restricted cubic splines.

\section{Results}

Of the 3106 eligible participants, $15.9 \%$ had prevalent diabetes, $19.0 \%$ in male and $13.7 \%$ in female, respectively. The median folate was significantly higher in diabetic patients than in controls (32.030 vs $27.600 \mu \mathrm{g}$ ), while median niacin was significantly lower (7.000 vs $7.900 \mathrm{mg})$. The binary logistic regression analysis also showed a significant association between dietary folate (Odds ratio $(O R)=1.002 ; 95 \%$ confidence interval $(\mathrm{Cl})$ : $1.000-1.004 ; \mathrm{P}=0.022$ ) and niacin intakes $(\mathrm{OR}=0.965 ; 95 \% \mathrm{Cl}: 0.944-0.986 ; \mathrm{P}=0.001)$ with the risk of diabetes after controlling for potential confounders. The plots of restricted cubic splines presented an atypical inverted U-shaped association between dietary folate intake and diabetes.

\section{Conclusions}

The data presented here showed that diabetics had a low intake of vitamins, especially B group vitamins. Dietary folate and niacin intakes tended to be independently related to the risk of diabetes. Nevertheless, this study is observational, and there yet to be large-scale randomized controlled trials which would increase the evidence of the findings.

\section{Background}

Diabetes is one of the fastest growing health challenges of the 21 st century, with the number of adults with diabetes having more than tripled over the past twenty years ${ }^{[1]}$. Diabetes has the potential to cause numerous debilitating health complications and increases the risk of early death ${ }^{[1]}$. Investment in effective diabetes prevention and management has become necessary to prevent disability and death.

It is well-known that diabetes is recognized as a multifactorial chronic disease that can be related to dietary factors ${ }^{\text {[2] }}$. Economic growth and environmental transitions have led to drastic changes in food production, processing, and distribution systems and have increased the accessibility of unhealthful foods. ${ }^{[3]}$ With nutritional transitions, people have experienced increased diabetes incidence and mortality. ${ }^{[4]}$

Several epidemiological studies ${ }^{[2,5-6]}$ have shown that diet plays an important role in the development of diabetes, and reported the association between nutrients intakes and the risk of diabetes ${ }^{[5-6]}$. In addition, people with diabetes should be informed about the importance of acquiring daily vitamin requirements through a well-balanced diet because people with poorly controlled diabetes often experience micronutrient deficiencies. ${ }^{[7]}$ Adequate $B$ vitamins intakes are a general 
requirement for healthy growth and nucleic acid synthesis in all cells. A few studies ${ }^{[8-15]}$ have reported that B group vitamins, especially folate (vitamin B9) and niacin (vitamin B3), may be involved in the pathogenesis of glucose intolerance and inversely associated with the risk of diabetes. However, the conclusions are inconsistent. Moreover, most of the previous studies were either for the vitamin status ${ }^{[16-17]}$ or supplemental ${ }^{[18-20]}$ rather than dietary intakes ${ }^{[10-11]}$.

Thus, it makes sense to explore the vitamin intakes in the diet and its association with the risk of diabetes. In view of this, the present study aimed to characterize dietary vitamin intakes in Chinese adults and to evaluate the associations between dietary vitamin intakes and the risk of diabetes, and hopefully to be able to provide a scientific rationale for formulating dietary guidelines.

\section{Methods}

\section{Study population}

A survey was conducted to explore the epidemiological characteristics of major chronic noncommunicable diseases among residents living in communities for more than 6 months selected by using a multistage random sampling design in Bengbu, China [21]. Individuals with severe mental illness or cognitive impairment and who were pregnant or breastfeeding were excluded. This cross-sectional study was reviewed and approved by the Ethics Committee of Bengbu medical college. All participants were required to complete the whole survey and sign informed consent.

\section{Data collection}

Demographic information was obtained through a questionnaire by trained staffs. The standardization of techniques and personnel training was performed before the start of the survey to reduce the inter-observer variations. Gender (male and female), age (years), educational level (elementary level or lower, junior high school level, high school level, and college level or higher), marital status (unmarried, currently married, and other), place of residence (urban and rural), cigarette smoking (current smoking and no smoking) were collected.

Anthropometric data were collected by trained staffs with uniform instruments. The height $(\mathrm{m})$ and weight $(\mathrm{kg})$ were ascertained in light indoor clothing, while the waist circumference $(\mathrm{cm})$ in a fasting state as well as an upright position. Body mass index (BMI) was calculated using weight $(\mathrm{kg})$ divided by squared height $(\mathrm{m})$, and BMl $\geq 28 \mathrm{~kg} / \mathrm{m}^{2}$ was set as general obesity ${ }^{[22]}$. Males with waist circumference $(\mathrm{WC}) \geq 90 \mathrm{~cm}$ and females with $\mathrm{WC} \geq 85 \mathrm{~cm}$ were considered abdominal obesity, respectively [23].

\section{Assessment of Diabetes}

Blood samples were collected after an overnight fast of more than eight hours. The individuals with diagnosed diabetes previously or fasting plasma glucose (FPG) value $\geq 7.0 \mathrm{mmol} / \mathrm{L}$ in this survey were defined as diabetes ${ }^{[24]}$.

\section{Assessment of vitamin intakes}

For the assessment of the vitamin intakes from diet, the three-day food record was used and the amounts of vitamins were calculated using the Food Nutrition Calculator V2.65 developed and recommended by National Institute of Nutrition and Food Safety, Chinese Center for Disease Control and Prevention.

\section{Statistical analyses}

The Kolmogorov-Smirnov test was applied to verify the normality of the data. Data for continuous variables were expressed as median (interquartile range), and categorical variables were expressed as number (percentages). MannWhitney $U$ tests and chi-square tests were used to compare the averages of continuous variables and the percentages of 
categorical variables between diabetes and normoglycemia group, respectively. Binary logistic regression models were used to examine the associations between dietary vitamin intakes and the risk of diabetes, adjusting for potential confounding variables. Variables included in the models were checked for multi-collinearity. We also used restricted cubic splines with four knots at the 25th, 50th, 75th, and 95th percentiles of the exposures distribution in fully adjusted model to flexibly model the association between dietary vitamin intakes and diabetes. All statistical analyses were undertaken using SPSS 23.0 (IBM, Armonk, NY, USA) and Stata 12.0 software (StataCorp., College Station, TX, USA). P<0.05 was considered statistically significant.

\section{Results}

\section{Characteristics of the study population}

A total of 3115 participants were recruited. Excluding 9 who did not complete the questionnaire regarding dietary vitamin intakes, 3106 were eventually included. The prevalence of diabetes was $15.9 \%, 19.0 \%$ in male and $13.7 \%$ in female, respectively. Diabetics had a higher median age (64y), compared with normoglycemia controls $(57 y, P<0.001)$.

Statistically significant differences of educational level $\left(X^{2}=19.731, P<0.001\right)$, marital status $\left(X^{2}=11.508, P=0.003\right)$ and place of residence $\left(X^{2}=8.467, P=0.004\right)$ between diabetics and normoglycemia controls were observed. There was a significantly higher proportion of smoking $\left(X^{2}=9.968, P=0.002\right)$, general obesity $\left(X^{2}=18.914, P<0.001\right)$ and abdominal obesity $\left(X^{2}=58.254, P<0.001\right)$ in the diabetes group compared with control group.

In terms of dietary vitamin intakes, median folate and vitamin $\mathrm{E}$ intakes were significantly higher in diabetic patients than in controls, while median thiamine, riboflavin, niacin and vitamin C intakes were significantly lower. Nevertheless, for vitamin A and vitamin B6, no significant differences were observed. The similar results were observed in women. Intake of niacin was lower in male diabetics than the controls. However, no other significant differences were observed in men. 
Characteristics of participants by diabetes status

\begin{tabular}{|c|c|c|c|c|}
\hline Variables & $\begin{array}{l}\text { Normoglycemia } \\
(n=2611)\end{array}$ & Diabetes $(n=495)$ & $\chi^{2} / Z$ value & P value \\
\hline Gender (Female) & $1556(59.6 \%)$ & 247 (49.9\%) & 16.061 & $<0.001$ \\
\hline Age (years) & $57(45,66)$ & $64(56,72)$ & -11.434 & $<0.001$ \\
\hline Educational level & & & 19.731 & $<0.001$ \\
\hline Elementary level or lower & 735 (28.2\%) & $187(37.9 \%)$ & & \\
\hline Junior high school level & $963(37.0 \%)$ & $170(34.4 \%)$ & & \\
\hline High school level & $646(24.8 \%)$ & $99(20.0 \%)$ & & \\
\hline College level or higher & $258(9.9 \%)$ & $38(7.7 \%)$ & & \\
\hline Marital status & & & 11.508 & 0.003 \\
\hline Unmarried & $92(3.5 \%)$ & $6(1.2 \%)$ & & \\
\hline Currently married & 2198 (84.8\%) & $411(83.5 \%)$ & & \\
\hline Other & $302(11.7 \%)$ & 75 (15.2\%) & & \\
\hline Place of residence & & & 8.467 & 0.004 \\
\hline Urban & $2156(82.6 \%)$ & $435(87.9 \%)$ & & \\
\hline Rural & $455(17.4 \%)$ & $60(12.1 \%)$ & & \\
\hline Smoking & $734(28.1 \%)$ & $174(35.2 \%)$ & 9.968 & 0.002 \\
\hline General obesity & $343(13.1 \%)$ & $102(20.6 \%)$ & 18.914 & $<0.001$ \\
\hline Abdominal obesity & $1036(39.7 \%)$ & $288(58.2 \%)$ & 58.254 & $<0.001$ \\
\hline \multicolumn{5}{|l|}{ Daily intake } \\
\hline Vitamin A ( $\mu g R E)$ & $280.000(134.000,500.000)$ & $285.000(155.000,435.000)$ & -0.068 & 0.946 \\
\hline Thiamine (mg) & $0.440(0.320,0.640)$ & $0.430(0.310,0.560)$ & -2.254 & 0.024 \\
\hline Riboflavin (mg) & $0.590(0.420,0.810)$ & $0.560(0.420,0.730)$ & -2.364 & 0.018 \\
\hline Vitamin B6 (mg) & $0.120(0.050,0.220)$ & $0.120(0.060,0.210)$ & -1.022 & 0.307 \\
\hline Folate $(\mu \mathrm{g})$ & $27.600(9.300,57.800)$ & $32.030(15.370,57.700)$ & -3.222 & 0.001 \\
\hline Niacin (mg) & $7.900(5.500,11.600)$ & $7.000(5.000,9.400)$ & -5.262 & $<0.001$ \\
\hline Vitamin C (mg) & $45.700(23.300,79.500)$ & $40.600(25.300,62.800)$ & -2.573 & 0.010 \\
\hline Vitamin E (mg) & $24.750(14.950,41.730)$ & $27.820(16.390,42.190)$ & -1.992 & 0.046 \\
\hline
\end{tabular}


Table 2

Dietary vitamin intakes between diabetes and controls according to gender

\begin{tabular}{|c|c|c|c|c|c|c|c|c|}
\hline Variables & Male & & & & Female & & & \\
\hline & $\begin{array}{l}\text { Normoglycemia } \\
(n=1055)\end{array}$ & $\begin{array}{l}\text { Diabetes } \\
(n=248)\end{array}$ & $\begin{array}{l}Z \\
\text { value }\end{array}$ & $\begin{array}{l}P \\
\text { value }\end{array}$ & $\begin{array}{l}\text { Normoglycemia } \\
(n=1556)\end{array}$ & $\begin{array}{l}\text { Diabetes } \\
(n=247)\end{array}$ & $\begin{array}{l}\mathrm{Z} \\
\text { value }\end{array}$ & $\begin{array}{l}\mathrm{P} \\
\text { value }\end{array}$ \\
\hline $\begin{array}{l}\text { Vitamin A } \\
(\mu g R E)\end{array}$ & $\begin{array}{l}285.000 \\
(143.000 \\
522.000)\end{array}$ & $\begin{array}{l}304.500 \\
(160.250 \\
454.750)\end{array}$ & -0.187 & 0.852 & $\begin{array}{l}274.500 \\
(127.250 \\
484.000)\end{array}$ & $\begin{array}{l}275.000 \\
(149.000 \\
407.000)\end{array}$ & -0.333 & 0.739 \\
\hline $\begin{array}{l}\text { Thiamine } \\
\text { (mg) }\end{array}$ & $\begin{array}{l}0.480(0.340 \\
0.710)\end{array}$ & $\begin{array}{l}0.480 \\
(0.340 \\
0.600)\end{array}$ & -1.392 & 0.164 & $\begin{array}{l}0.420(0.300 \\
0.590)\end{array}$ & $\begin{array}{l}0.400 \\
(0.280 \\
0.500)\end{array}$ & -2.788 & 0.005 \\
\hline $\begin{array}{l}\text { Riboflavin } \\
\text { (mg) }\end{array}$ & $\begin{array}{l}0.620(0.450 \\
0.880)\end{array}$ & $\begin{array}{l}0.570 \\
(0.453 \\
0.768)\end{array}$ & -1.853 & 0.064 & $\begin{array}{l}0.570(0.400 \\
0.780)\end{array}$ & $\begin{array}{l}0.530 \\
(0.400 \\
0.700)\end{array}$ & -2.230 & 0.026 \\
\hline $\begin{array}{l}\text { Vitamin } \\
\text { B6 (mg) }\end{array}$ & $\begin{array}{l}0.120(0.060 \\
0.240)\end{array}$ & $\begin{array}{l}0.130 \\
(0.070 \\
0.210)\end{array}$ & -0.055 & 0.956 & $\begin{array}{l}0.100(0.040 \\
0.210)\end{array}$ & $\begin{array}{l}0.110 \\
(0.060 \\
0.190)\end{array}$ & -0.924 & 0.355 \\
\hline $\begin{array}{l}\text { Folate } \\
(\mu \mathrm{g})\end{array}$ & $\begin{array}{l}30.800(11.300 \\
64.900)\end{array}$ & $\begin{array}{l}35.730 \\
(17.765 \\
57.120)\end{array}$ & -1.427 & 0.154 & $\begin{array}{l}25.250(8.200 \\
54.750)\end{array}$ & $\begin{array}{l}28.470 \\
(13.800 \\
58.200)\end{array}$ & -2.538 & 0.011 \\
\hline $\begin{array}{l}\text { Niacin } \\
(\mathrm{mg})\end{array}$ & $\begin{array}{l}9.000(6.200 \\
13.600)\end{array}$ & $\begin{array}{l}7.800 \\
(5.648 \\
10.230)\end{array}$ & -4.298 & $<0.001$ & $\begin{array}{l}7.200(5.100 \\
10.500)\end{array}$ & $\begin{array}{l}6.270 \\
(4.670 \\
8.300)\end{array}$ & -4.515 & $<0.001$ \\
\hline $\begin{array}{l}\text { Vitamin C } \\
(\mathrm{mg})\end{array}$ & $\begin{array}{l}45.100(22.500 \\
78.700)\end{array}$ & $\begin{array}{l}41.650 \\
(25.425 \\
64.875)\end{array}$ & -1.047 & 0.295 & $\begin{array}{l}46.200(23.825 \\
80.075)\end{array}$ & $\begin{array}{l}38.900 \\
(25.200 \\
61.400)\end{array}$ & -2.540 & 0.011 \\
\hline $\begin{array}{l}\text { Vitamin } \mathrm{E} \\
(\mathrm{mg})\end{array}$ & $\begin{array}{l}26.210(15.850 \\
44.140)\end{array}$ & $\begin{array}{l}28.425 \\
(16.055 \\
43.483)\end{array}$ & -0.429 & 0.668 & $\begin{array}{l}23.840(14.535 \\
40.100)\end{array}$ & $\begin{array}{l}26.360 \\
(16.620 \\
40.110)\end{array}$ & -2.106 & 0.035 \\
\hline
\end{tabular}

\section{Regression Analysis}

After adjusting for gender, age, educational level, marital status, place of residence, smoking, general obesity and abdominal obesity, the binary logistic regression analysis revealed that participants with diabetes had greater OR for folate intake (OR = 1.002; 95\% Cl: 1.000-1.004; $\mathrm{P}=0.022)$ and lower OR for niacin intake (OR = 0.965; 95\% Cl: 0.944-0.986; $\mathrm{P}=0.001)$ than did those with normoglycemia.

In the adjusted regression models stratified by gender, OR for niacin intake for comparing male diabetics with controls were $0.970(0.945,0.996)$, while in the female participants OR for folate and riboflavin intakes were $1.004(1.001,1.006)$ and $0.593(0.393,0.893)$, respectively. The multi-collinearity was checked, and no obvious collinearity was noted. 
Table 3

Predictors of diabetes using the binary logistic regression analysis

\begin{tabular}{|c|c|c|c|c|}
\hline \multirow[t]{2}{*}{ Variables } & \multirow[t]{2}{*}{ OR $(95 \% \mathrm{Cl})$} & \multirow[t]{2}{*}{$P$ value } & \multicolumn{2}{|c|}{ Collinearity } \\
\hline & & & TOL & VIF \\
\hline Gender (Female) & $0.657(0.536,0.805)$ & $<0.001$ & 0.585 & 1.711 \\
\hline Age (year) & $1.037(1.029,1.045)$ & $<0.001$ & 0.682 & 1.467 \\
\hline WC (Abdominal obesity) & $1.840(1.503,2.252)$ & $<0.001$ & 0.830 & 1.205 \\
\hline Folate $(\mu \mathrm{g})$ & $1.002(1.000,1.004)$ & 0.022 & 0.660 & 1.516 \\
\hline Niacin (mg) & $0.965(0.944,0.986)$ & 0.001 & 0.419 & 2.387 \\
\hline
\end{tabular}

Table 4

Predictors of diabetes according to gender

\begin{tabular}{|c|c|c|c|c|c|c|c|c|}
\hline \multirow[t]{3}{*}{ Variables } & \multicolumn{4}{|l|}{ Male } & \multicolumn{4}{|l|}{ Female } \\
\hline & \multirow[t]{2}{*}{ OR $(95 \% \mathrm{Cl})$} & \multirow{2}{*}{$\begin{array}{l}\mathrm{P} \\
\text { value }\end{array}$} & \multicolumn{2}{|c|}{ Collinearity } & \multirow[t]{2}{*}{ OR $(95 \% \mathrm{Cl})$} & \multirow{2}{*}{$\begin{array}{l}P \\
\text { value }\end{array}$} & \multicolumn{2}{|c|}{ Collinearity } \\
\hline & & & TOL & VIF & & & TOL & VIF \\
\hline Age (year) & $\begin{array}{l}1.024(1.013 \\
1.035)\end{array}$ & $<0.001$ & 0.707 & 1.414 & $\begin{array}{l}1.052(1.040 \\
1.064)\end{array}$ & $<0.001$ & 0.652 & 1.534 \\
\hline $\begin{array}{l}\text { Place of residence } \\
\text { (Urban) }\end{array}$ & $\begin{array}{l}0.569(0.362 \\
0.895)\end{array}$ & 0.015 & 0.786 & 1.273 & - & - & - & - \\
\hline General obesity & - & - & - & - & $\begin{array}{l}1.458(1.015 \\
2.096)\end{array}$ & 0.041 & 0.855 & 1.170 \\
\hline Abdominal obesity & $\begin{array}{l}1.378(1.035 \\
1.834)\end{array}$ & 0.028 & 0.850 & 1.176 & $\begin{array}{l}2.089(1.532, \\
2.848)\end{array}$ & $<0.001$ & 0.804 & 1.244 \\
\hline Riboflavin (mg) & - & - & - & - & $\begin{array}{l}0.593(0.393 \\
0.893)\end{array}$ & 0.012 & 0.405 & 2.469 \\
\hline Folate $(\mu \mathrm{g})$ & - & - & - & - & $\begin{array}{l}1.004(1.001 \\
1.006)\end{array}$ & 0.002 & 0.626 & 1.598 \\
\hline Niacin (mg) & $\begin{array}{l}0.970(0.945 \\
0.996)\end{array}$ & 0.024 & 0.426 & 2.349 & - & - & - & - \\
\hline
\end{tabular}

\section{Restricted Cubic Spline}

Figure 1 and Figure 2 depicted the results of the restricted cubic spline analyses. The odds ratios of diabetes increased with increasing folate intakes until around $36.8 \mu \mathrm{g}$ and then started to decrease. The ORs of diabetes increased with the increase of niacin intakes until around $6.9 \mathrm{mg}$, then showed a reduction until $20.2 \mathrm{mg}$, and then increased thereafter.

\section{Discussion}

In the present study, a prevalence of diabetes of $15.9 \%$ was reported, suggesting that it was prevalent in Chinese adults. This study also investigated the relationship between the intake of each vitamin with diabetes and found that dietary 
folate and vitamin $E$ intakes were significantly higher in diabetic patients than in controls, while dietary thiamine, riboflavin, niacin and vitamin $\mathrm{C}$ intakes were significantly lower. After adjusting for potential confounders, subjects with diabetes had a greater odds ratio for dietary folate intake and lower OR for niacin intake in comparison to those without diabetes. In addition, the plots of restricted cubic splines presented an inverted U-shaped association between dietary folate intake and the risk of diabetes. According to gender, there were significant differences in the folate intake for women, and niacin intake for men between the diabetes and normoglycemia groups.

B group vitamins are essential water-soluble nutrients. Folate (vitamin B9) can be found in a wide variety of food, such as vegetables, fruits and nuts ${ }^{[25]}$. Dietary intake of folate was inversely associated with incident diabetes in Korean or Japanese women reported by previous two prospective cohort studies ${ }^{[10-11]}$. Diabetes is an oxidative stress disease, folate deficiency has been linked to oxidative stress in diabetic patients ${ }^{[8]}$. Deficiency of folate has also been reported to severely hamper biosynthesis and secretion of insulin in pancreatic $\beta$-cells ${ }^{[26]}$. However, our study showed that people with diabetes had higher dietary folate intakes than the controls. The anti-diabetes drug metformin may cause folate deficiency. In an randomized controlled trial (RCT), after eight weeks of folate supplementation, diabetic men taking metformin showed improved serum total antioxidant capacity [27]. Thus, there is a possibility that higher folate intake in diabetics may be due to the reverse causality. The diabetics might have been advised to change their dietary habits during routine examinations.

Niacin (vitamin B3) can be found in meat (especially liver and heart), fish, nuts, and some fruits and vegetables and coffee ${ }^{[28]}$. Niacin is known to lower triglycerides and low-density lipoprotein cholesterol levels while significantly increasing high-density lipoprotein cholesterol levels ${ }^{[29]}$. Few studies have assessed the relationship between dietary niacin intake and diabetes. Inadequate intake of niacin from food may have not been recognized as a problem. The present study indicated that individuals with low niacin intake had a high likelihood of having diabetes. However, a Japanese study concluded that dietary intake of niacin was not associated with a reduced risk of diabetes ${ }^{[11]}$. An RCT study ${ }^{[30]}$ showed that the use of niacin for 3 years in subjects with normal baseline glucose levels was associated with an increase in blood glucose levels and the risk of developing impaired fasting glucose. While Sazonov et al. ${ }^{[14]}$ reported that niacin has clinically insignificant negative impact on glycaemia. However, further research about the relationship between dietary niacin intake and the risk of diabetes is needed.

Thiamine, also known as vitamin B1, plays a role in various cell functions, such as energy metabolism and the breakdown of sugars and carbon skeletons ${ }^{[31]}$. Riboflavin, also known as vitamin B2, plays a role in tryptophan metabolism, iron

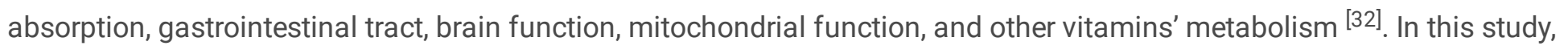
the dietary intakes of thiamine and riboflavin in diabetic patients were significantly lower than that in the control group. Moreover, riboflavin intake was independently associated with the risk of diabetes in women. Insufficient thiamine level causes inadequate glucose metabolism in mitochondria ${ }^{[31]}$. Taking thiamine for a month has been shown to decrease glucose in diabetics when compared to controls ${ }^{[33]}$. Meanwhile, Md Maroof Alam et al. ${ }^{[34]}$ suggested that supplementation with dietary riboflavin might help in the reduction of diabetic complications.

Vitamins $\mathrm{C}$ as an antioxidant was found decreased in diabetic patients, possibly due to an increased need to control the excessive oxidative stress caused by abnormal glucose metabolism ${ }^{[8]}$. Plasma vitamin $\mathrm{C}$ concentrations have been significantly and inversely associated with glycosylated hemoglobin and fasting and postprandial blood glucose and oxidative stress ${ }^{[35-36]}$. Vitamin E has a very important antioxidant role in the organism and has been found decreased in patients with diabetes ${ }^{[37]}$. However, other studies have shown no association with risk of diabetes or no effect on insulin sensitivity ${ }^{[38-39]}$. Our study showed lower dietary vitamin $C$ and higher vitamin $E$ intakes in diabetic patients. The effect of vitamins $\mathrm{C}$ and vitamin $\mathrm{E}$ on the risk of diabetes is likely due to its role as an antioxidant. 
Several potential limitations warrant mention. First, this study is a cross-sectional design, which does not allow to establish the temporality of cause-effect relationship with certainty. Second, the information of using glucose-lowering drugs or vitamin supplements was not investigated, which may have affected the results. Third, vitamin intake data were obtained through a three-day dietary questionnaire review, which could not accurately reflect an individual's dietary intake due to faulty memory and underreporting. Finally, the study sample was recruited in Bengbu city and was not necessarily representative of all the general populations, which may limit the generalizability of our findings. In spite of this, we have adjusted for some known and proposed potential confounders for reliability in binary logistic regression models and restricted cubic splines analyses, and our findings added to the limited data available on the association of dietary vitamin intakes with the risk of diabetes in Chinese populations.

\section{Conclusions}

In conclusion, a dose response relationship between dietary folate and niacin intakes with the odds ratios of diabetes suggest the importance of these kind of vitamins rich diet in the management of diabetes. As vitamin intakes is a simple and feasible indicator of diabetes, increasing B group vitamins intakes among adults may offer promise as a costeffective strategy to improve diabetes. Larger longitudinal and interventional studies are needed to quantify preventive and therapeutic levels of dietary vitamin intakes, especially the folate and niacin, for control of diabetes in clinical practice.

\section{List Of Abbreviations}

OR, Odds ratio

$\mathrm{Cl}$, confidence interval

BMI, Body mass index

WC, waist circumference

FPG, fasting plasma glucose

TOL, Tolerance

VIF, Variance Inflation Factor

RCT, Randomized Controlled Trial

\section{Declarations}

\section{Ethics approval and consent to participate}

This study was approved by the Ethics Committee of Bengbu medical college. All participants were required to complete the whole survey and sign informed consent.

\section{Consent for publication}

Not applicable.

\section{Availability of data and materials}


The datasets used and/or analysed during the current study are available from the corresponding author on reasonable request.

\section{Competing interests}

The authors declare that they have no competing interests.

\section{Funding}

This study was supported by Humanities and Social Sciences Planning Fund Project of the Ministry of Education of China (No. 15YJAZH085) and Teaching research project of Education Department of Anhui Province (No. 2019jxtd070).

\section{Author contributions}

All authors contributed to the study conception and design. Material preparation, data collection and analysis were performed by Yuhong Jiang, Zhiwen Zhang, Yi Zhu and Yongfei Chai. The first draft of the manuscript was written by Yuhong Jiang and Hong Xie, and all authors commented on previous versions of the manuscript. All authors read and approved the final manuscript.

\section{Acknowledgements}

Not applicable.

\section{References}

1. International Diabetes Federation. [accessed August 26, 2021]; IDF Diabetes Atlas. (9). 2019 https://diabetesatlas.org/en/

2. Zaroudi M, Yazdani Charati J, Mehrabi S, Ghorbani E, et al. Dietary patterns are associated with risk of diabetes type 2: a population-based case-control study. Arch Iran Med. 2016;19(3):166-172.

3. Popkin BM, Adair LS, Ng SW. Global nutrition transition and the pandemic of obesity in developing countries. Nutr Rev. 2012;70(1):3-21.

4. Ezzati M, Riboli E. Behavioral and dietary risk factors for noncommunicable diseases. N Engl J Med. 2013;369(10):954-64.

5. Cooper AJ, Sharp SJ, Lentjes MA, et al. A prospective study of the association between quantity and variety of fruit and vegetable intake and incident type 2 diabetes. Diabetes Care. 2012;35:1293-1300. doi: 10.2337/dc11-2388.

6. Sluijs I, Beulens JW, van der AD, et al. Dietary intake of total, animal, and vegetable protein and risk of type 2 diabetes in the European Prospective Investigation into Cancer and Nutrition (EPIC)-NL study. Diabetes Care. 2010;33:43-48. doi: 10.2337/dc09-1321.

7. Evert AB, Boucher JL, Cypress M, et al. Nutrition therapy recommendations for the management of adults with diabetes. Diabetes Care. 2014; 37(Supplement 1): S120-S43.

8. Valdés-Ramos R, Guadarrama-López AL, Martínez-Carrillo BE, Benítez-Arciniega AD. Vitamins and type 2 diabetes mellitus. Endocr Metab Immune Disord Drug Targets. 2015; 15: 54-63. doi: 10.2174/1871530314666141111103217.

9. Mursleen MT, Riaz S. Implication of homocysteine in diabetes and impact of folate and vitamin B12 in diabetic population. Diabetes Metab Syndr. 2017;11(Suppl 1):S141-S146. doi: 10.1016/j.dsx.2016.12.023.

10. Sang M Hong, Hey W Woo, Mi K Kim, Se Y Kim, Young-Hoon Lee, Dong H Shin, Min-Ho Shin, Byung-Yeol Chun, Bo Y Choi. A prospective association between dietary folate intake and type 2 diabetes risk among Korean adults aged 40 years or older: the Korean Multi-Rural Communities Cohort (MRCohort) Study. Br J Nutr. 2017 Dec;118(12):10781088. doi: 10.1017/S0007114517003087. 
11. Ehab S Eshak, Hiroyasu Iso, Isao Muraki, Akiko Tamakoshi. Among the water-soluble vitamins, dietary intakes of vitamins C, B2 and folate are associated with the reduced risk of diabetes in Japanese women but not men. Br J Nutr. 2019 Jun;121(12):1357-1364. doi: 10.1017/S000711451900062X.

12. Jie Zhu, Cheng Chen, Liping Lu, Kefeng Yang, Jared Reis, Ka He. Intakes of Folate, Vitamin B6, and Vitamin B12 in Relation to Diabetes Incidence Among American Young Adults: A 30-Year Follow-up Study. Diabetes Care. 2020 Oct;43(10):2426-2434. doi: 10.2337/dc20-0828.

13. Binh An P Phan, Luis Muñoz, Pey Shadzi, Daniel Isquith, Michael Triller, B Greg Brown, Xue-Qiao Zhao. Effects of niacin on glucose levels, coronary stenosis progression, and clinical events in subjects with normal baseline glucose levels (<100 mg/dl): a combined analysis of the Familial Atherosclerosis Treatment Study (FATS), HDL-

Atherosclerosis Treatment Study (HATS), Armed Forces Regression Study (AFREGS), and Carotid Plaque Composition by MRI during lipid-lowering (CPC) study. Am J Cardiol. 2013;111(3):352-5. doi: 10.1016/j.amjcard.2012.09.034.

14. V Sazonov, D Maccubbin, C McCrary Sisk, P L Canner. Effects of niacin on the incidence of new onset diabetes and cardiovascular events in patients with normoglycaemia and impaired fasting glucose. Int J Clin Pract. 2013 Apr;67(4):297-302. doi: 10.1111/ijcp.12089.

15. Yi Ding, YuWen Li, AiDong Wen. Effect of niacin on lipids and glucose in patients with type 2 diabetes: A metaanalysis of randomized, controlled clinical trials. Clin Nutr. 2015 Oct;34(5):838-44. doi: 10.1016/j.clnu.2014.09.019.

16. Georgia Kanti, Evrim Anadol-Schmitz, Pavel Bobrov, Klaus Strassburger, Sabine Kahl, Oana P Zaharia, Theresia Sarabhai, Yanislava Karusheva, Volker Burkart, Daniel F Markgraf, Sandra Trenkamp, Dan Ziegler, Julia Szendroedi, Michael Roden, GDS Group. Vitamin B12 and Folate Concentrations in Recent-onset Type 2 Diabetes and the Effect of Metformin Treatment. J Clin Endocrinol Metab. 2020 Jun 1;105(6):dgaa150. doi: 10.1210/clinem/dgaa150.

17. Shi-Sheng Zhou, Da Li, Wu-Ping Sun, Ming Guo, Yong-Zhi Lun, Yi-Ming Zhou, Fu-Cheng Xiao, Li-Xin Jing, Shen-Xia Sun, Li-Bin Zhang, Ning Luo, Fu-Ning Bian, Wei Zou, Lai-Bin Dong, Zhi-Gang Zhao, Sheng-Fan Li, Xiao-Jie Gong, ZengGuo Yu, Chang-Bin Sun, Cong-Long Zheng, Dong-Ju Jiang, Zheng-Ning Li. Nicotinamide overload may play a role in the development of type 2 diabetes. World J Gastroenterol. 2009; 15(45): 5674-84. doi: 10.3748/wjg.15.5674.

18. Patcharaporn Sudchada, Surasak Saokaew, Sorattaya Sridetch, Siriwan Incampa, Sopida Jaiyen, Warangkana Khaithong. Effect of folic acid supplementation on plasma total homocysteine levels and glycemic control in patients with type 2 diabetes: a systematic review and meta-analysis. Diabetes Res Clin Pract. 2012 Oct;98(1):151-8. doi: 10.1016/j.diabres.2012.05.027.

19. Christina Goldie, Allen J Taylor, Peter Nguyen, Cody McCoy, Xue-Qiao Zhao, David Preiss. Niacin therapy and the risk of new-onset diabetes: a meta-analysis of randomised controlled trials. Heart. 2016 Feb;102(3):198-203. doi:

10.1136/heartjnl-2015-308055.

20. Dan Xiang, Qian Zhang, Yang-Tian Wang. Effectiveness of niacin supplementation for patients with type 2 diabetes: A meta-analysis of randomized controlled trials. Medicine (Baltimore). 2020 Jul 17;99(29):e21235. doi: 10.1097/MD.0000000000021235.

21. Hong Xie, Jian Song, Liangliang Sun, Xinxin Xie, Yehuan Sun. Independent and combined effects of triglycerideglucose index on prehypertension risk: a cross-sectional survey in China [J]. J Hum Hypertens. 2021; 35(3): $207-214$. doi: 10.1038/s41371-020-0321-9.

22. Chen C, Lu FC, Department of Disease Control Ministry of Health, PR China. The guidelines for prevention and control of overweight and obesity in Chinese adults. Biomed Environ Sci. 2004;17:1-36.

23. Chu JR, Gao JL, Zhao SP, Lu GP, Zhao D, Li JJ. Blood lipid abnormity prevention guidance in Chinese adult. Chin Circulation J. 2016;31:937-53.

24. Alberti KG, Zimmet PZ. Definition, diagnosis and classification of diabetes mellitus and its complications. Part 1 : diagnosis and classification of diabetes mellitus provisional report of a WHO consultation. Diabet Med. 1998; 15 : $539-553$.

Page $11 / 14$ 
25. Jie V Zhao, C Mary Schooling, Jia Xi Zhao. The effects of folate supplementation on glucose metabolism and risk of type 2 diabetes: a systematic review and meta-analysis of randomized controlled trials. Ann Epidemiol. 2018 Apr;28(4):249-257.e1. doi: 10.1016/j.annepidem.2018.02.001.

26. Hung-Chih Hsu, Jeng-Fong Chiou, Yu-Huei Wang, Chia-Hui Chen, Shin-Yi Mau, Chun-Te Ho, Pey-Jium Chang, TsanZon Liu, Ching-Hsein Chen. Folate deficiency triggers an oxidative-nitrosative stress-mediated apoptotic cell death and impedes insulin biosynthesis in RINm5F pancreatic islet $\beta$-cells: relevant to the pathogenesis of diabetes. PLoS One. 2013 Nov 4;8(11):e77931. doi: 10.1371/journal.pone.0077931.

27. Aghamohammadi V, Gargari B.P, Aliasgharzadeh A. Effect of folic acid supplementation on homocysteine, serum total antioxidant capacity, and malondialdehyde in patients with type 2 diabetes mellitus. J. Am. Coll. Nutr. 2011; 30(3): 210-215. doi: 10.1080/07315724.2011.10719962.

28. M Carola Zillikens, Joyce B J van Meurs, Eric J G Sijbrands, Fernando Rivadeneira, Abbas Dehghan, Johannes P T M van Leeuwen, Albert Hofman, Cornelia M van Duijn, Jacqueline C M Witteman, André G Uitterlinden, Huibert A P Pols. SIRT1 genetic variation and mortality in type 2 diabetes: interaction with smoking and dietary niacin. Free Radic Biol Med. 2009 Mar 15;46(6):836-41. doi: 10.1016/j.freeradbiomed.2008.12.022.

29. Kei A, Elisaf MS. Nicotinic acid: clinical considerations [J]. Expert Opinion on Drug Safety, 2012, 11(4): 551-64.

30. Binh An P Phan, Luis Muñoz, Pey Shadzi, Daniel Isquith, Michael Triller, B Greg Brown, Xue-Qiao Zhao. Effects of niacin on glucose levels, coronary stenosis progression, and clinical events in subjects with normal baseline glucose levels (<100 mg/dl): a combined analysis of the Familial Atherosclerosis Treatment Study (FATS), HDLAtherosclerosis Treatment Study (HATS), Armed Forces Regression Study (AFREGS), and Carotid Plaque Composition by MRI during lipid-lowering (CPC) study. Am J Cardiol. 2013;111(3):352-5. doi: 10.1016/j.amjcard.2012.09.034.

31. Manzetti, S.; Zhang, J.; van der Spoel, D. Thiamin function, metabolism, uptake, and transport. Biochemistry 2014, 53, 821-835.

32. Thakur, K.; Tomar, S.K.; Singh, A.K.; Mandal, S.; Arora, S. Riboflavin and health: A review of recent human research. Crit. Rev. Food Sci. Nutr. 2017, 57, 3650-3660.

33. GonzA lez-Ortiz M, MartA-nez-Abundis E, Robles-Cervantes J.A, RamA-rez-RamA-rez V, Ramos-Zavala M.G. Effect of thiamine administration on metabolic profile, cytokines and inflammatory markers in drug-naïve patients with type 2 diabetes. Eur. J. Nutr. 2011; 50(2): 145-149. doi: 10.1007/s00394-010-0123-x.

34. Md Maroof Alam, Sarah Iqbal, Imrana Naseem. Ameliorative effect of riboflavin on hyperglycemia, oxidative stress and DNA damage in type-2 diabetic mice: Mechanistic and therapeutic strategies. Arch Biochem Biophys. 2015; 584: 10-9. doi: 10.1016/j.abb.2015.08.013.

35. Carter P, Gray L.J, Talbot D, Morris D.H, Khunti K, Davies M.J. Fruit and vegetable intake and the association with glucose parameters: a cross-sectional analysis of the Let's Prevent Diabetes Study. Eur. J. Clin. Nutr. 2013; 67(1): 1217. doi: 10.1038/ejcn.2012.174.

36. Mazloom Z, Hejazi N, Dabbaghmanesh M.H, Tabatabaei H.R, Ahmadi A, Ansar H. Effect of vitamin C supplementation on postprandial oxidative stress and lipid profile in type 2 diabetic patients. Pak. J. Biol. Sci. 2011; 14(19): 900-904. doi: 10.3923/pjbs.2011.900.904.

37. Odum E.P, Ejilemele A.A, Wakwe V.C. Antioxidant status of type 2 diabetic patients in Port Harcourt, Nigeria. Niger. J. Clin. Pract. 2012; 15(1): 55-58. doi: 10.4103/1119-3077.94099.

38. M K Kataja-Tuomola, J P Kontto, S Männistö, D Albanes, J Virtamo. Intake of antioxidants and risk of type 2 diabetes in a cohort of male smokers. Eur J Clin Nutr. 2011; 65(5): 590-7. doi: 10.1038/ejcn.2010.283.

39. Suksomboon N, Poolsup N, Sinprasert S. Effects of vitamin E supplementation on glycaemic control in type 2 diabetes: systematic review of randomized controlled trials. J. Clin. Pharm. Ther. 2011; 36(1): 53-63. doi: 10.1111/j.1365-2710.2009.01154.x. 


\section{Figures}

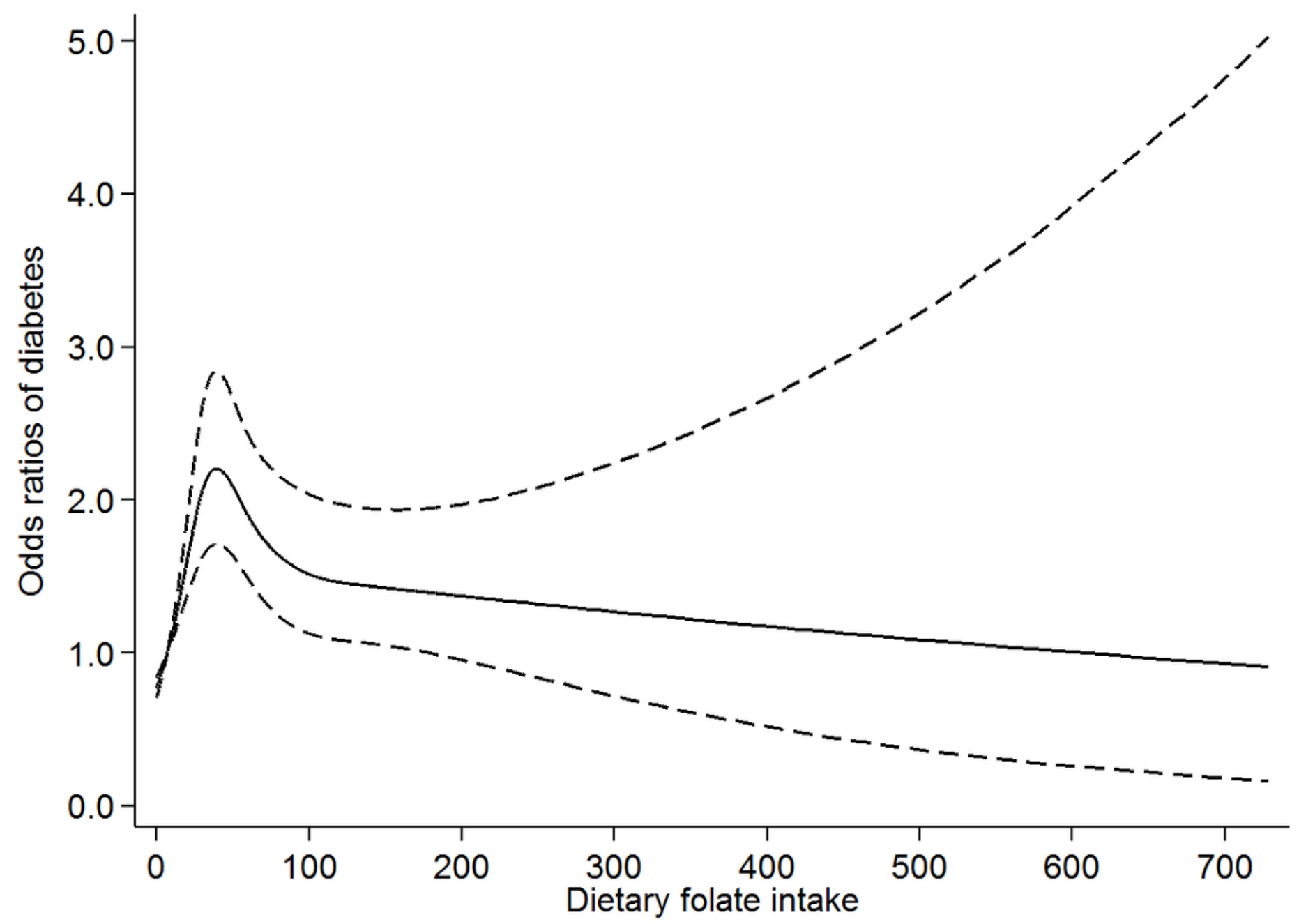

Figure 1

Restricted cubic spline model of the odds ratios of diabetes with dietary folate intake. Adjusted for gender, age, educational level, marital status, place of residence, smoking, general obesity and abdominal obesity. The dashed lines represent the $95 \%$ confidence intervals. 


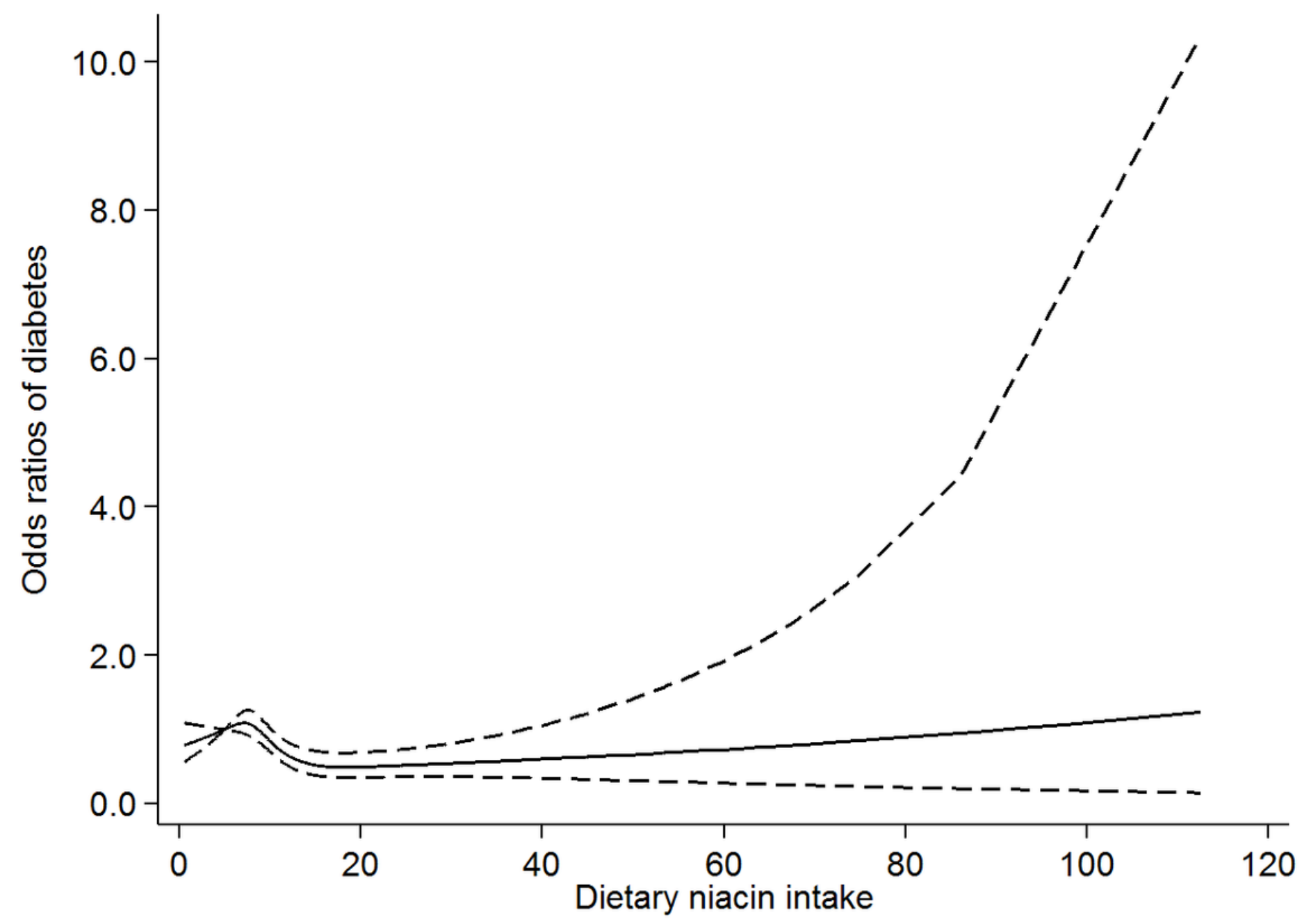

Figure 2

Restricted cubic spline model of the odds ratios of diabetes with dietary niacin intake. Adjusted for gender, age, educational level, marital status, place of residence, smoking, general obesity and abdominal obesity. The dashed lines represent the $95 \%$ confidence intervals. 